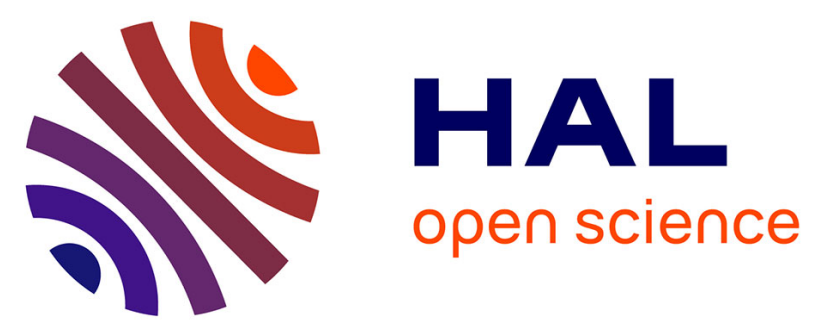

\title{
Neither variation loss, nor change in selfing rate is associated with the worldwide invasion of [i]Physa acuta[/i] from its native North America
}

\author{
Lydia Bousset, J. -P. Pointier, Patrice David, Philippe Jarne
}

\section{To cite this version:}

Lydia Bousset, J. -P. Pointier, Patrice David, Philippe Jarne. Neither variation loss, nor change in selfing rate is associated with the worldwide invasion of $[\mathrm{i}] \mathrm{Physa}$ acuta[/i] from its native North America. Biological Invasions, 2014, 16 (8), pp.1769-1783. 10.1007/s10530-013-0626-5 . hal-01208728

\section{HAL Id: hal-01208728 \\ https://hal.science/hal-01208728}

Submitted on 27 May 2020

HAL is a multi-disciplinary open access archive for the deposit and dissemination of scientific research documents, whether they are published or not. The documents may come from teaching and research institutions in France or abroad, or from public or private research centers.
L'archive ouverte pluridisciplinaire HAL, est destinée au dépôt et à la diffusion de documents scientifiques de niveau recherche, publiés ou non, émanant des établissements d'enseignement et de recherche français ou étrangers, des laboratoires publics ou privés.

$$
\text { Copyright }
$$




\title{
Neither variation loss, nor change in selfing rate is associated with the worldwide invasion of Physa acuta from its native North America
}

\author{
L. Bousset $\cdot$ J.-P. Pointier $\cdot$ P. David $\cdot$ \\ P. Jarne
}

Received: 19 April 2013/Accepted: 16 December 2013/Published online: 24 December 2013

(C) Springer Science+Business Media Dordrecht 2013

\begin{abstract}
Whether bioinvasions are associated with a loss of genetic diversity and a change in mating system is instrumental for understanding the evolutionary fate of invasive species. Little loss is expected under strong propagule pressure which might be a general situation in widespread, efficient invader. In hermaphroditic species, we have few examples of a transition between outcrossing and selfing as a consequence of invasion, though this is classically predicted (as a corollary to Baker's law). We estimated microsatellite variation in 44 populations of the widespread freshwater snail Physa acuta sampled at worldwide scale (including several populations from its native North America). Neither loss of variation (or bottleneck), nor increase in selfing rate was detected in invaded areas. Moreover there was no isolation by distance at large geographic scale, and limited
\end{abstract}

Electronic supplementary material The online version of this article (doi:10.1007/s10530-013-0626-5) contains supplementary material, which is available to authorized users.

L. Bousset

UMR 1349 IGEPP, INRA, 35653 Le Rheu Cedex, France

J.-P. Pointier

USR 3278 CNRS-EPHE CRIOBE, Université de

Perpignan, 68860 Perpignan Cedex, France

P. David · P. Jarne ( $\square)$

CEFE UMR 5175, Campus CNRS, 1919 Route de Mende,

34293 Montpellier Cedex, France

e-mail: philippe.jarne@cefe.cnrs.fr geographic coherence in genetic patterns was detected using STRUCTURE software-the West Mediterranean area being an exception. Such patterns might be explained by (1) multiple introductions in the invaded areas, presumably fostered by aquarium trade, followed by regional spread in some cases-in which case mating partners might be numerous enough to prevent transition towards higher selfing rates, and (2) invasions from the whole native area. This suggests that $P$. acuta is an exceptionally efficient invader (which is not true of related species), but the reasons of its success remain elusive.

Keywords Bioinvasions - Genetic diversity · Mating systems $\cdot$ Phylogeography $\cdot$ Physa acuta . Snail

\section{Introduction}

Bioinvasions offer excellent opportunities for studying the evolutionary process, as their spatio-temporal dynamics depends not only on ecological, but also on evolutionary forces (Lee 2002; Sax et al. 2005; Facon et al. 2006; Davis 2008). Evolutionary biologists have been particularly interested by several questions with regard to bioinvasions, including (1) their origin and history (see Dlugosh and Parker 2008; Estoup and Guillemaud 2010; Lawson Handley et al. 2011), (2) the evolutionary forces at work (Lee 2002; Sax et al. 2005; Facon et al. 2006), and (3) their consequences 
on the distribution of genetic variation, and therefore on adaptation and mating systems (Kolbe et al. 2004; Barrett et al. 2007; Facon et al. 2008). We are interested here in the first aspect, and especially in the last one. With regard to the origin and history of invaders, freshwater organisms deserve special attention (see Roman and Darling 2007; Beisel and Levêque 2010). As other organisms, they usually rely on migration to reach new environments, especially on passive migration, for example through birds, over long distances. However the trade of aquarium plants (e.g., in invertebrates) and intentional introductions (e.g., in fish) now are much more efficient vectors of passive migration (Padilla and Williams 2004; Hayes et al. 2008; Duggan 2010). Migration, whether active or passive, can strongly affect the subsequent build-up and distribution of variation in the invaded areas (Sax et al. 2005; Facon et al. 2008).

The consequences of bioinvasions on variation have essentially been evaluated on neutral molecular variation (Roman and Darling 2007; Dlugosh and Parker 2008; Lawson Handley et al. 2011). Bioinvasions have for some time been thought to lead to depressed variation as they were assumed to coincide with bottlenecks and founder effects. Recent reviews indicate that the loss of variation is on average limited (Dlugosh and Parker 2008), and enhanced variation might also be observed as the result of both repeated introductions and local hybridization (Wares et al. 2005; Roman and Darling 2007; Dlugosh and Parker 2008). For the same reason, invasions might not lead to increased differentiation in the invaded areas compared to the native areas following founder effect, but this has been less considered (Novak and Mack 2005; Barrett et al. 2007). The mating system might also interfere with variation loss following invasion. For example, selfing plants seem to lose variation whereas this does not occur in outcrossers, perhaps because variation segregates more among than within populations in selfers, limiting the buildup of variation through recurrent migration (Novak and Mack 2005). In self-compatible hermaphrodites, strong genetic bottlenecks, low density of mating partners or absence of pollinators might also lead to increased selfing rates (Kirkpatrick and Jarne 2000; Cheptou 2012), but very few examples have been documented (see Barrett et al. 2007 in plants). Hermaphroditic species of freshwater snails exhibit variation in the selfing rate, though intermediate selfing rates (i.e. around 0.5) are rare (Jarne and Auld 2006; Escobar et al. 2011). In this group, both predominantly outcrossing and predominantly selfing species have become biological invaders in various places (e.g., Pointier et al. 2005), but whether invasion can induce a transition in mating system remains to be documented.

We focus on the freshwater snail Physa acuta, an hermaphroditic species belonging to the Physidae (freshwater Pulmonates). The systematics of this family has been recently clarified by the phylogenetic work of Wethington and Lydeard (2007) suggesting that several named species indeed belong to a complex of closely allied species. On the whole there might be no more than 20 species of Physidae (see also Jarne et al. 2010). P. acuta itself includes several deep mtDNA clades, i.e. exhibiting rather large molecular divergence (of the order of $6 \%$ at $16 \mathrm{~S}$ rDNA and COI genes; Wethington and Lydeard 2007). This species which has been known under a plethora of species names (see Dillon et al. 2002) is the Physidae (and perhaps the mollusc) species exhibiting the largest distribution area as a result of recent expansion. Knowledge about its native area and invasion history is sketchy (Dillon et al. 2002). P. acuta originates from East of the Rocky Mountains in North America, but the available information prevents to be more specific in geographic terms. The first argument about this origin relies on the fact that most physid species originates from this very same area (New World), especially the species most closely allied to $P$. acuta (Wethington and Lydeard 2007). A stronger argument derives from the timing of species description in the physids. P. acuta was first described in Europe in 1805, and in North America in 1817 only (Dillon et al. 2002). However several common species, such as Radix peregra or the congeneric Physa fontinalis, were described as early as 1760 . Given that $P$. acuta is easily distinguished from all other European freshwater snails and is also a very common species, its late description is suggestive of a first European invasion at the beginning of the nineteenth century. That it was described later in North America than in Europe is explained by the fact that the first descriptions of North American freshwater gastropods were performed by Say in 1817. Other continents might have been invaded later than Europe, but this is poorly documented (see e.g. Brown 1994; Albrecht et al. 2009). P. acuta is today ubiquitous on Earth, occupying 
freshwater environments from the Equator to the Polar circles, including remote islands. Note that no other physid species is invasive to the exception of the neotropical Aplexa marmorata (Bony et al. 2007) which invasion remains though limited to a few African countries. P. acuta has been studied with regard to various issues in evolutionary biology, especially species limit (Dillon et al. 2002, 2011), life-history traits, mating systems, sexual selection and senescence (e.g. Jarne et al. 2000; Escobar et al. 2008, 2009; Pélissié et al. 2012). Its population structure has been analyzed using genetic markers at local scale (Bousset et al. 2004; Dillon and Wethington 2006; Escobar et al. 2008; Van Leeuwen et al. 2013), but never at a geographic scale that can provide insights into its recent expansion.

Given the scale at which invasion took place in $P$. acuta, this species can be considered as an excellent biological model for analyzing bioinvasions at a very large geographic scale. We studied the distribution of microsatellite variation (preferred here to DNA sequences given the pretty recent history of invasion) in 44 populations sampled from both the native and invaded (worldwide scale) areas. Our objectives were (1) to improve our knowledge about the invasion history of $P$. acuta, and (2) to evaluate whether invasion has been associated with depletion of genetic variation and change in selfing rate.

\section{Materials and methods}

Sampling and characterization of microsatellite variation

Physa acuta is a cosmopolitan species occupying a wide range of habitats. Populations fluctuate widely, sometimes rising to extremely high densities (e.g., thousands of individuals $/ \mathrm{m}^{2}$; adults are about $10-15 \mathrm{~mm}$ in shell length), in connection with variation in water availability. Four hundred and fifty-five individuals were sampled in 44 sites representing a variety of habitats at worldwide scale, essentially between 1999 and 2002 (Table 1). They were euthanized in hot water for 30-60 s before being stored in $90^{\circ}$ ethanol, and sent to our laboratory in Montpellier. Species status was checked upon arrival based on outside individual phenotypes (see also below for molecular identification). Populations Mos1, FL, FRJ,
Co and UCh have already been used in a population genetic analysis at much smaller geographic scale (Bousset et al. 2004). We also sampled individuals $(\mathrm{N}=66)$ in one to three sites of the allied species Physa gyrina, Physa fontinalis and Aplexa marmorata (SI Table 1).

Twelve individuals were generally analyzed per site, sometimes less (Table 2). Population genetic estimates should therefore be regarded with caution. DNA extraction (QiAmp Tissue kit, Qiagen), microsatellite characterisation and locus scoring on an ABI 310 sequencer were performed according to Sourrouille et al. (2003) and Bousset et al. (2004). Nine loci were analyzed (Monsutti and Perrin 1999; Sourrouille et al. 2003), four of which are dinucleotide repeats (Pac1, AF108758, AF108762, AF108764) and the other five are tetranucleotide repeats (Pac2, Pac4, Pac5, Pac7, Pac14). PCR amplification was performed either on single loci (Pac 14, AF108758), or on locus groups (Pac1, Pac2 and Pac5; Pac4 and Pac7; AF108762 and AF108764). Electrophoretic runs were conducted separately on two locus groups (Pac1, Pac2, Pac4, Pac5, Pac7, AF108762 and AF108764; Pac14 and AF108758). The subsequent analyses were limited to six loci (Pac1, Pac2, Pac5, AF108758, AF108762 and AF108764), because of the high frequency of null alleles at the three remaining loci. Null alleles were for example fixed in 6, 2 and 2 samples (181, 105 and 18 individuals respectively out of 455) at loci Pac4, Pac7 and Pac14 respectively.

Within-population genetic diversity and demography

The genetic variability was described in each population using the number of alleles $\left(\mathrm{N}_{\mathrm{all}}\right)$ rarefied to six individuals (see Petit et al. 1998), the observed heterozygosity $\left(\mathrm{H}_{\mathrm{o}}\right)$ and the gene diversity $\left(\mathrm{H}_{\mathrm{e}}\right)$ adjusted for small samples, averaged over all loci (Nei 1987). Deviations from the genotypic proportions expected at Hardy-Weinberg equilibrium (HWE) at each locus and from genotypic equilibrium between locus pairs were tested in each population using exact tests (Rousset and Raymond 1995). Departure from HWE over all loci was evaluated using Fisher's method for combining probabilities. The unbiased estimator $\hat{f}$ of Wright's $\mathrm{F}_{\text {is }}$ was calculated according to Weir and Cockerham (1984). The calculations and 


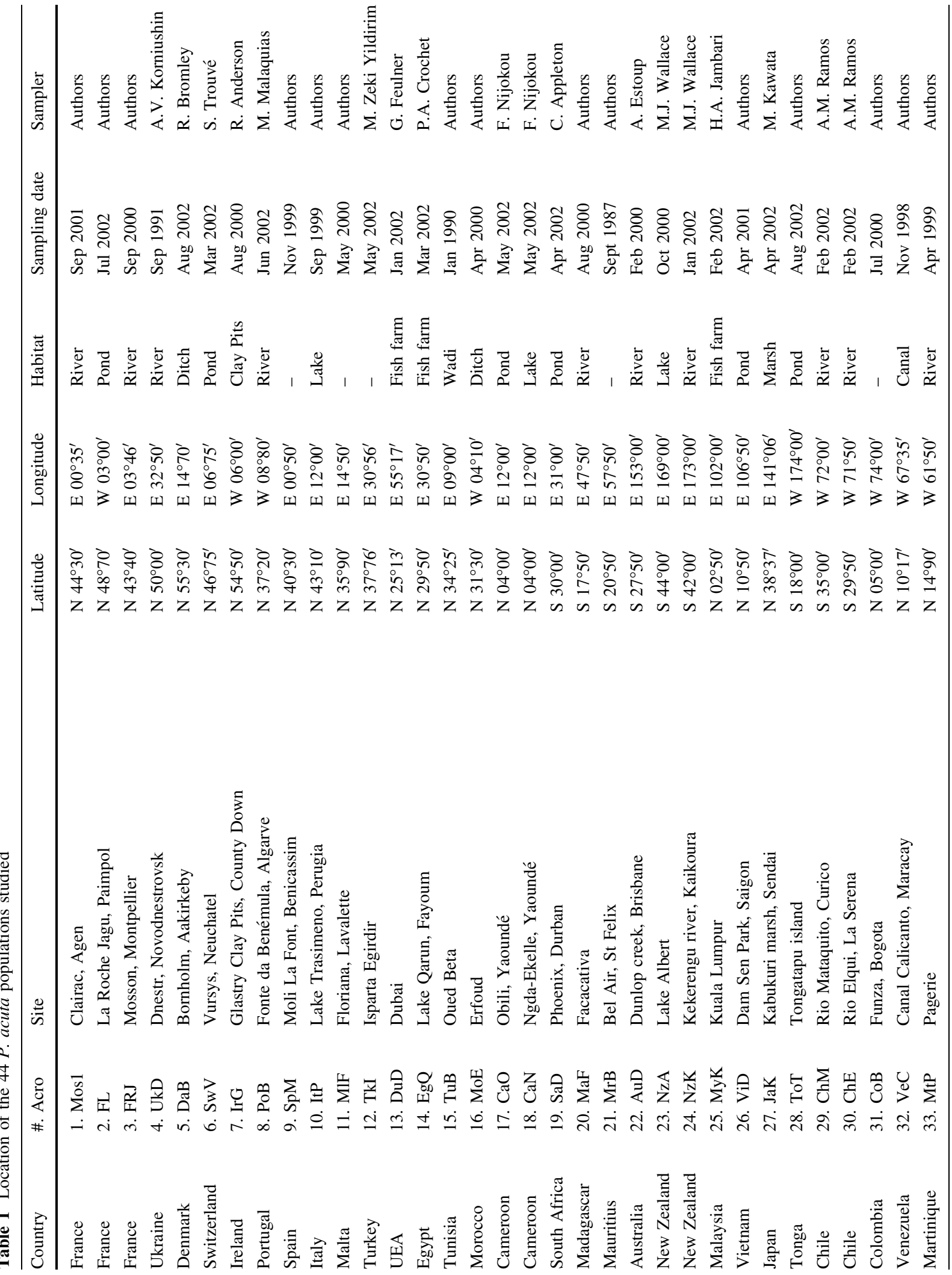




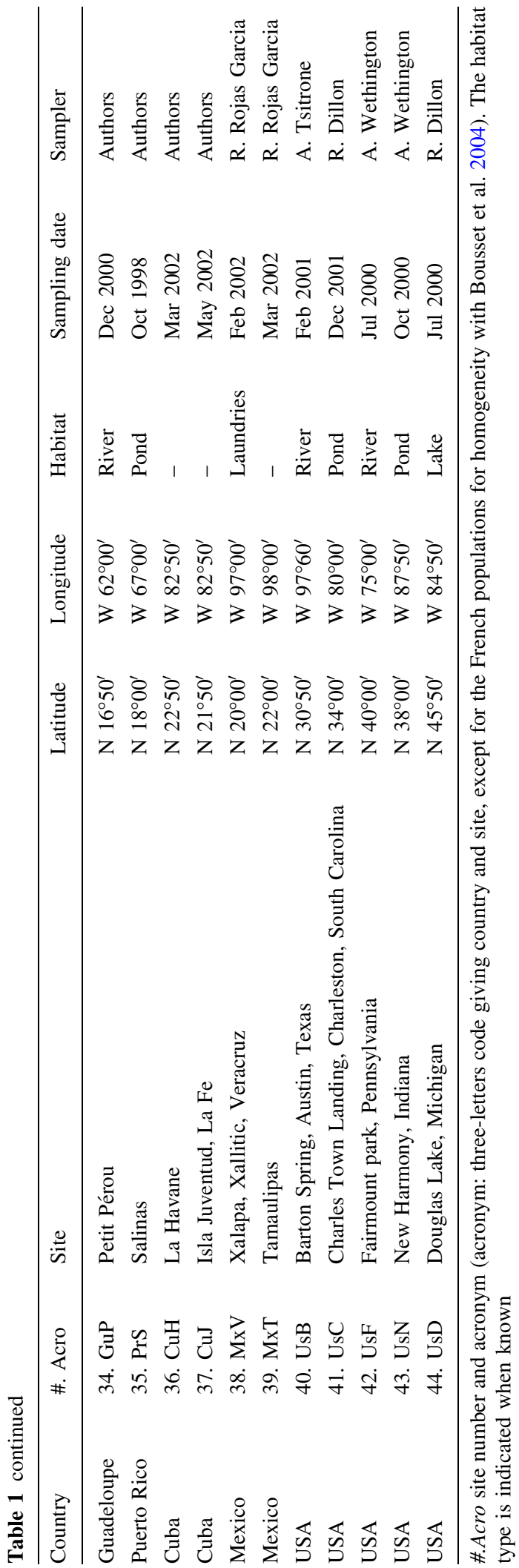

tests above were performed using GENEPOP 3.1 (Raymond and Rousset 1995). We estimated the selfing rate using the relationship $\hat{s}=2 \hat{f} /(1+\hat{f})$ (Pollak 1987). $\hat{f}$ is upwardly biased by null alleles and other technical artifacts transforming heterozygotes into homozygotes (see Jarne and David 2008). The selfing rate was therefore also estimated using the multilocus method implemented in RMES software (David et al. 2007) which has been designed to be insensitive to such artifacts.

The demographic history of populations was evaluated using the method of Cornuet and Luikart (1996). These methods are based on the excess of heterozygosity expected in a population which size has suddenly decreased, and then remained constant. Tests were conducted for the three types of mutation models proposed (Infinite Allele Model, IAM; Stepwise Mutation Model, SMM; Two-Phased Model, TPM). This last model is arguably the most realistic given our knowledge of mutation models at microsatellites (Jarne and Lagoda 1996; Ellegren 2004). The heterozygosity excess was evaluated over loci in the populations with more than 10 individuals using Wilcoxon signed-ranks tests implemented with BOTTLENECK software (Cornuet and Luikart 1996).

The allelic richness and expected heterozygosities were compared between populations exhibiting signals of bottleneck versus other populations, as well as between populations from the native area and other populations. Given the uncertainty about the exact limits of the native area, tests were conducted considered as native, either USA populations, or USA and Mexican populations (the later ones are located on the Caribbean coast, not far south from the USA boarder). This was done using an analysis of variance (using an ArcSin (square root) transformation for expected heterozygosity data), allowing to test whether invasion was associated with variability loss.

\section{Differentiation among populations and phylogeography}

Genetic differentiation was analysed per locus for all population pairs using a homogeneity test (Goudet et al. 1996) computed as an exact test. The estimator $\hat{\theta}$ of $F_{\text {st }}$ (Weir and Cockerham 1984) was calculated over all loci, both over all populations and all population pairs. All tests and calculations were performed with 
Table 2 Variation at six microsatellite loci in the 44 populations sampled

\begin{tabular}{|c|c|c|c|c|c|c|c|c|}
\hline Population & $\mathrm{N}$ & $\mathrm{N}_{\mathrm{p}}$ & $\mathrm{R}_{\mathrm{a}}$ & $\mathrm{H}_{\mathrm{e}}$ & $\mathrm{H}_{\mathrm{o}}$ & $\hat{f}$ & $P$ & $\mathrm{~S}$ \\
\hline 1. Mos1 & 12 & 5 & 3.438 (1.337) & $0.619(0.153)$ & $0.694(0.172)$ & -0.128 & 0.034 & 0.004 \\
\hline 2. FL & 12 & 5 & $2.371(0.895)$ & $0.387(0.293)$ & $0.264(0.295)$ & 0.327 & 0.003 & 0.019 \\
\hline 3. FRJ & 21 & 5 & $2.973(0.674)$ & $0.579(0.155)$ & $0.548(0.150)$ & 0.056 & 0.234 & 0.010 \\
\hline 4. UkD & 12 & 4 & $2.463(1.058)$ & $0.363(0.242)$ & $0.306(0.228)$ & 0.164 & 0.070 & 0.254 \\
\hline 5. $\mathrm{DaB}$ & 12 & 6 & $3.692(1.636)$ & $0.557(0.204)$ & $0.489(0.216)$ & 0.128 & 0.073 & 0.064 \\
\hline 6. SwV & 12 & 5 & $3.045(0.800)$ & $0.533(0.190)$ & $0.375(0.302)$ & 0.306 & 0.000 & 0.016 \\
\hline 7. $\mathrm{IrG}$ & 12 & 4 & $2.904(1.196)$ & $0.516(0.235)$ & $0.294(0.255)$ & 0.440 & 0.000 & 0.044 \\
\hline 8. $\mathrm{PoB}$ & 12 & 6 & $2.476(0.597)$ & $0.433(0.195)$ & $0.389(0.195)$ & 0.106 & 0.185 & 0.230 \\
\hline 9. SpM & 12 & 5 & $3.300(1.201)$ & $0.528(0.240)$ & $0.486(0.200)$ & 0.082 & 0.186 & 0.008 \\
\hline 10. ItP & 12 & 6 & $2.960(0.634)$ & $0.579(0.093)$ & $0.361(0.164)$ & 0.386 & 0.000 & 0.031 \\
\hline 11. MlF & 12 & 4 & $2.384(0.902)$ & $0.444(0.266)$ & $0.431(0.266)$ & 0.032 & 0.402 & 0.023 \\
\hline 12. TkI & 3 & 1 & $1.700(0.837)$ & $0.211(0.333)$ & $0.222(0.344)$ & -0.066 & 0.332 & - \\
\hline 13. $\mathrm{DuD}$ & 12 & 5 & $2.557(1.086)$ & $0.440(0.230)$ & $0.438(0.274)$ & 0.005 & 0.517 & 0.000 \\
\hline 14. EgQ & 6 & 4 & $2.167(0.753)$ & $0.389(0.230)$ & $0.361(0.195)$ & 0.078 & 0.394 & - \\
\hline 15. TuB & 10 & 5 & $2.714(0.607)$ & $0.568(0.064)$ & $0.367(0.103)$ & 0.366 & 0.000 & 0.021 \\
\hline 16. MoE & 12 & 5 & $2.564(1.094)$ & $0.441(0.282)$ & $0.361(0.256)$ & 0.188 & 0.044 & 0.194 \\
\hline 17. $\mathrm{CaO}$ & 12 & 5 & $2.623(1.025)$ & $0.486(0.257)$ & $0.319(0.331)$ & 0.352 & 0.000 & 0.005 \\
\hline 18. $\mathrm{CaN}$ & 12 & 3 & $1.940(1.063)$ & $0.279(0.286)$ & $0.278(0.287)$ & 0.005 & 0.554 & 0.071 \\
\hline 19. $\mathrm{SaD}$ & 9 & 5 & $2.315(0.492)$ & $0.487(0.127)$ & $0.468(0.391)$ & 0.043 & 0.376 & 0.158 \\
\hline 20. $\mathrm{MaF}$ & 12 & 5 & $3.071(1.575)$ & $0.463(0.301)$ & $0.333(0.167)$ & 0.289 & 0.000 & 0.016 \\
\hline 21. MrB & 12 & 6 & $1.890(0.597)$ & $0.338(0.240)$ & $0.259(0.208)$ & 0.242 & 0.038 & 0.088 \\
\hline 22. AuD & 9 & 5 & $2.483(0.888)$ & $0.480(0.251)$ & $0.389(0.208)$ & 0.200 & 0.088 & - \\
\hline 23. NzA & 12 & 5 & $2.821(1.163)$ & $0.471(0.307)$ & $0.444(0.297)$ & 0.059 & 0.305 & 0.013 \\
\hline 24. NzK & 6 & 5 & $2.167(0.753)$ & $0.303(0.211)$ & $0.333(0.236)$ & -0.111 & 0.153 & - \\
\hline 25. МyК & 12 & 6 & $2.720(1.658)$ & $0.407(0.263)$ & $0.389(0.287)$ & 0.046 & 0.358 & 0.010 \\
\hline 26. ViD & 12 & 3 & $2.349(0.941)$ & $0.311(0.258)$ & $0.194(0.146)$ & 0.385 & 0.000 & 0.698 \\
\hline 27. JaK & 12 & 6 & $2.927(0.865)$ & $0.501(0.175)$ & $0.319(0.178)$ & 0.373 & 0.000 & 0.093 \\
\hline 28. ToT & 12 & 5 & $2.871(1.139)$ & $0.509(0.219)$ & $0.264(0.123)$ & 0.492 & 0.000 & 0.213 \\
\hline 29. ChM & 6 & 4 & $2.667(1.366)$ & $0.470(0.366)$ & $0.250(0.329)$ & 0.491 & 0.000 & - \\
\hline 30. ChE & 12 & 5 & $3.148(1.540)$ & $0.530(0.308)$ & $0.375(0.267)$ & 0.301 & 0.001 & 0.295 \\
\hline 31. CoB & 12 & 3 & $1.484(0.531)$ & $0.178(0.208)$ & $0.208(0.246)$ & -0.179 & 0.050 & 0.012 \\
\hline 32. $\mathrm{VeC}$ & 12 & 6 & $2.638(0.934)$ & $0.569(0.123)$ & $0.458(0.156)$ & 0.201 & 0.036 & 0.115 \\
\hline 33. MtP & 12 & 4 & $1.828(0.566)$ & $0.193(0.137)$ & $0.184(0.142)$ & 0.047 & 0.345 & 0.685 \\
\hline 34. GuP & 12 & 5 & $3.378(1.380)$ & $0.553(0.194)$ & $0.403(0.162)$ & 0.300 & 0.001 & 0.015 \\
\hline 35. $\operatorname{PrS}$ & 6 & 4 & $2.833(1.169)$ & $0.578(0.303)$ & $0.417(0.274)$ & 0.299 & 0.016 & - \\
\hline 36. $\mathrm{CuH}$ & 6 & 5 & $2.569(1.002)$ & $0.450(0.178)$ & $0.306(0.324)$ & 0.341 & 0.012 & - \\
\hline 37. $\mathrm{CuJ}$ & 12 & 6 & $2.720(0.823)$ & $0.523(0.295)$ & $0.312(0.211)$ & 0.414 & 0.000 & 0.399 \\
\hline 38. MxV & 12 & 3 & $1.777(0.731)$ & $0.248(0.250)$ & $0.222(0.328)$ & 0.109 & 0.251 & 0.295 \\
\hline 39. MxT & 12 & 5 & $2.943(1.737)$ & $0.431(0.285)$ & $0.264(0.193)$ & 0.398 & 0.000 & 0.367 \\
\hline 40. UsB & 12 & 5 & $4.786(2.291)$ & $0.684(0.294)$ & $0.375(0.137)$ & 0.463 & 0.000 & 0.011 \\
\hline 41. UsC & 10 & 6 & $3.603(1.004)$ & $0.602(0.163)$ & $0.583(0.232)$ & 0.032 & 0.386 & 0.009 \\
\hline 42. UsF & 6 & 4 & $2.333(0.816)$ & $0.407(0.287)$ & $0.417(0.361)$ & -0.027 & 0.333 & - \\
\hline 43. UsN & 6 & 4 & $3.167(1.722)$ & $0.528(0.347)$ & $0.583(0.391)$ & -0.117 & 0.078 & - \\
\hline
\end{tabular}


Table 2 continued

\begin{tabular}{lllllllll}
\hline Population & $\mathrm{N}$ & $\mathrm{N}_{\mathrm{p}}$ & $\mathrm{R}_{\mathrm{a}}$ & $\mathrm{H}_{\mathrm{e}}$ & $\mathrm{H}_{\mathrm{o}}$ & $\hat{f}$ & $P$ & $\mathrm{~S}$ \\
\hline 44. UsD & 12 & 3 & $1.619(0.573)$ & $0.127(0.134)$ & $0.139(0.155)$ & -0.094 & 0.000 & 0.110 \\
\hline
\end{tabular}

$N$ is the sample size and $N_{p}$ the number of polymorphic loci. $R_{a}, H_{e}$ and $H_{o}$ are the allelic richness (rarefied to $\mathrm{N}=6$ individuals), Nei's unbiased gene diversity and the observed heterozygosity over all loci respectively. Their standard deviations are indicated into parentheses. $\hat{f}$ is the estimate of Wright's $F_{i s}$ and $P$ is the probability associated with the corresponding exact test (deviation) of Hardy-Weinberg proportions. $S$ is the estimate of the selfing rate using the maximum likelihood method of David et al. (2007) (estimated when $\mathrm{N}>10)$. The only significant value $(P<0.05)$ is indicated in bold characters

GENEPOP 3.1. We also estimated $F_{\text {st }}$ using the method of Chapuis and Estoup (2007) in order to evaluate the influence of null alleles on population differentiation. This was done using FreeNA software (Chapuis and Estoup 2007). Independence between geographic and genetic distances of population pairs (isolation by distance) was tested using the Mantellike procedure implemented in GENETIX 4.05 (Belkhir et al. 2004). The geographic distance was the shortest distance between two sampling points, estimated according to the formula provided in Viard et al. (1997) that accounts for earth curvature. The genetic distance was the logarithm of $\mathrm{F}_{\mathrm{st}} /\left(1-\mathrm{F}_{\mathrm{st}}\right)$ as advocated by Rousset (1997).

Population clustering was inferred using STRUCTURE v2.3 software (Falush et al. 2003) under the admixture model using all populations. Runs were conducted for a number of clusters $(\mathrm{K})$ ranging from 1 to 15 , and 20 runs were performed for each $\mathrm{K}$ value. The ranked likelihood ( $\mathrm{K}$ from 1 to 15 ) saturated at $\mathrm{K}=8-10$, and we followed Evanno et al. (2005) for inferring the most likely cluster number. Populations were attributed to a cluster when their probability was larger than 0.8 - the population probability is returned as the average unweighted probability over all individuals (we also discuss below the case of populations with probability larger than 0.6 ).

\section{Results}

Within-population genetic diversity and demography

None of the nine loci used provided any amplification products in $P$. gyrina, $P$. fontinalis and A. marmorata, whatever the geographical origin of the samples (Table S1). This was expected given that the phylogenetic distances between $P$. acuta and these species are of the order of several millions of years, whatever the molecular clock assumed (Wethington and Lydeard 2007). These microsatellite loci can therefore be used to exclude individuals of these species falsely identified as $P$. acuta individuals, as can also be mitochondrial DNA sequences (Wethington and Lydeard 2007).

The six loci used in P. acuta exhibited from six (1B) to 30 (58B) alleles (overall mean 14.66, s.d. 9.39) at study scale. One to six loci were polymorphic per population (Table 2). The allelic richness averaged over loci (rarefied to six individuals) ranged from 1.48 to 4.91 , and gene diversity $\left(\mathrm{H}_{\mathrm{e}}\right)$ from 0.127 to 0.684 (Table 2). The observed $\mathrm{H}_{\mathrm{o}}$ was generally lower than gene diversity, often resulting in heterozygote deficiencies. Of the 235 possible tests of deviation from HW proportions at locus-population combinations, 110 were significant at the $5 \%$ level (46 when applying a brute-force Bonferroni test). Significant deviations were evenly distributed across loci although more significant values were detected at locus Pac5. The multilocus tests per population were significant in 28 populations (Table 2). The estimates of $\mathrm{F}_{\text {is }}$ over all loci ranged from -0.179 to 0.492 (Table 2). However the RMES multilocus population estimates of the selfing rate were not significantly different from 0 , to the exception of that from population ViD (Vietnam). The estimate over all populations was $3.7 \times 10^{-4}(95 \% \mathrm{CI} 0-0.084)$. None of the tests of genotypic disequilibrium between loci pairs over all populations were significant and only $2.5 \%$ of the tests performed within population for 1,210 locus pairs were significant, which is lower than the number of significant tests expected by chance.

The tests for bottleneck detection gave different results depending on the mutation model (Table 3 ). The null hypothesis of mutation-drift equilibrium was not rejected in many populations, whatever the mutational model. A signal of bottleneck (heterozygosity excess) 
Table 3 Results of tests on mutation-drift equilibrium

\begin{tabular}{|c|c|c|c|c|c|c|}
\hline Pop & IAM & & TPM & & SMM & \\
\hline 1. Mos 1 & 0.002 & Exc. & 0.01 & Exc. & 0.13 & \\
\hline 2. FL & 0.03 & Exc. & 0.19 & & 0.47 & \\
\hline 3. FRJ & 0.04 & Exc. & 0.19 & & 0.27 & \\
\hline 4. UkD & 0.23 & & 0.34 & & 0.71 & \\
\hline 5. $\mathrm{DaB}$ & 0.50 & & 0.88 & & 0.94 & \\
\hline 6. SwV & 0.03 & Exc. & 0.37 & & 0.77 & \\
\hline 7. $\mathrm{IrG}$ & 0.19 & & 0.37 & & 0.68 & \\
\hline 8. $\mathrm{PoB}$ & 0.13 & & 0.63 & & 0.02 & Def. \\
\hline 9. SpM & 0.21 & & 0.59 & & 0.79 & \\
\hline 10. ItP & 0.005 & Exc. & 0.10 & & 0.5 & \\
\hline 11. MlF & 0.004 & Exc. & 0.02 & Exc. & 0.03 & Exc. \\
\hline 13. DuD & 0.10 & & 0.37 & & 0.68 & \\
\hline 15. TuB & 0.002 & Exc. & 0.002 & Exc. & 0.002 & Exc. \\
\hline 16. $\mathrm{MoE}$ & 0.13 & & 0.13 & & 0.16 & \\
\hline 17. $\mathrm{CaO}$ & 0.01 & Exc. & 0.02 & Exc. & 0.23 & \\
\hline 18. $\mathrm{CaN}$ & 0.04 & Exc. & 0.08 & & 0.42 & \\
\hline 20. $\mathrm{MaF}$ & 0.18 & & 0.50 & & 0.88 & \\
\hline 21. MrB & 0.10 & & 0.41 & & 0.5 & \\
\hline 23. NzA & 0.16 & & 0.32 & & 0.47 & \\
\hline 25. МyK & 0.02 & Exc. & 0.18 & & 0.5 & \\
\hline 26. ViD & 0.88 & & 0.02 & Def. & 0.005 & Def. \\
\hline 27. JaK & 0.10 & & 0.41 & & 0.79 & \\
\hline 28. ToT & 0.03 & Exc. & 0.13 & & 0.27 & \\
\hline 30. $\mathrm{ChE}$ & 0.04 & Exc. & 0.13 & & 0.37 & \\
\hline 31. $\mathrm{CoB}$ & 0.01 & Exc. & 0.02 & Exc. & 0.04 & Exc. \\
\hline 32. $\mathrm{VeC}$ & 0.001 & Exc. & 0.001 & Exc. & 0.003 & Exc. \\
\hline 33. $\mathrm{MtP}$ & 0.71 & & 0.95 & & 0.98 & Def. \\
\hline 34. GuP & 0.41 & & 0.59 & & 0.63 & \\
\hline 37. CuJ & 0.001 & Exc. & 0.01 & Exc. & 0.15 & \\
\hline 38. MxV & 0.04 & Exc. & 0.05 & & 0.28 & \\
\hline 39. MxT & 0.41 & & 0.71 & & 0.88 & \\
\hline 40. UsB & 0.10 & & 0.19 & & 0.53 & \\
\hline 41. UsC & 0.01 & Exc. & 0.10 & & 0.5 & \\
\hline 44. UsD & 1.00 & & 0.004 & Def. & 0.004 & Def. \\
\hline
\end{tabular}

BOTTLENECK software was run under the IAM, the TPM and SMM in populations with more than 10 individuals (see Table 2). The table gives the probability associated with Wilcoxon signed-ranks test of the null hypothesis of equilibrium. 'Exc.' and 'Def.' hold respectively for excess and deficit (when $P \leq 0.05$ ) indicating respectively a bottleneck and an expansion

occurred under the IAM in half of the 34 populations tested, but this model is arguably the least likely of the three models used. More conservatively considering only those cases in which the conclusions were similar under the three mutation models, no heterozygosity deficit (genetic signal of population expansion) was detected. Two cases were detected if we consider the TPM and SMM only (ViD and UsD). A genetic signal of bottleneck was detected in four populations (MlF, $\mathrm{TuB}, \mathrm{CoB}$ and $\mathrm{VeC}$ ) for the three mutation models (Table 3). Considering the (most likely) TPM only the number of bottleneck signals rises to seven, all in populations outside USA/Mexico.

No significant difference in allelic richness and gene diversity was detected between populations showing or not a signal of bottleneck whether considering the four or seven populations just mentioned ( $F$ test, $P>0.160, \mathrm{~N}=34$ populations). This was also true when considering allelic richness in USA and other populations, or USA/Mexico versus other populations $(P=0.905$ and 0.095 respectively; $\mathrm{N}=$ all 44 populations), although there was slightly less variation in invaded areas. For example, the allelic richness for the USA/Mexico populations was 3.10 (s.d. 1.126) vs. 2.68 (s.d. 0.602) for other populations. We note that the USA population UsD exhibits extremely low variability. The same comparisons for gene diversity were not significant either $(P=0.771$ and 0.678 respectively).

Differentiation among populations and phylogeography

Differentiation tests between population pairs over all loci were all significant $\left(P<10^{-4}\right)$, a single one (between the two populations from Switzerland) approaching the $5 \%$ significance level $(P=0.043)$ and 18 tests only exhibiting a probability larger than 0.01 (Table S2). The overall $\mathrm{F}_{\text {st }}$ estimate was 0.352 (CI 0.326-0.389; based on 1,000 bootstraps), and the pairwise estimates over all loci ranged from 0.035 to 0.821 (mean $=0.359$; Table S2). The extremely high values are partially explained by small sample sizes. We also estimated $F_{\text {st }}$ among population pairs using FreeNA software in order to account for null alleles. The mean value over all population pairs was higher by $2 \%$ only than the one estimated without taking into account null alleles ( 0.359 vs. 0.366$)$. No isolation by distance was detected at overall scale (Mantel-like test, $P=0.363$ ).

STRUCTURE analysis indicated that the most likely number of clusters is six based on the approach of Evanno et al. (2005) (Table 4; Figure 
Table 4 Population clusters returned by STRUCTURE analysis
The six clusters are numbered from 1 to 6 . (A) Twenty-eight populations were affected to a cluster with $P>0.8$ (italic characters) and nine with $P>0.6$. (B) For the remaining seven populations, we provide the two clusters with the highest probability. NorthAmerican populations are indicated in bold characters. See Table 1 for acronyms and Fig. 1 for spatial distribution

\begin{tabular}{|c|c|c|c|c|c|}
\hline \multicolumn{6}{|l|}{ A. } \\
\hline 1 & 2 & 3 & 4 & 5 & 6 \\
\hline 6. $S w V$ & 1. $F L$ & 32. $\mathrm{VeC}$ & 13. $D u D$ & 2. FRJ & 38. $\mathrm{MxV}$ \\
\hline 31. $C o B$ & 3. MosI & 33. $M t P$ & 25. $M y K$ & 4. $U k D$ & 39. MxT \\
\hline \multirow[t]{6}{*}{ 36. $\mathrm{CuH}$} & 8. $Р o B$ & 41. UsC & 26. $V i D$ & 16. $M o E$ & 44. UsD \\
\hline & 9. $S p M$ & & 27. $\mathrm{JaK}$ & 18. $\mathrm{CaN}$ & \\
\hline & 11. $M l F$ & & 34. GuP & 21. $M r B$ & \\
\hline & 14. $E g Q$ & & & 28. ToT & \\
\hline & 19. $S a D$ & & & & \\
\hline & 23. $\mathrm{NzK}$ & & & & \\
\hline \multirow[t]{3}{*}{ 42. UsF } & 10. ItP & 29. ChM & 7. IrG & 5. DaB & 35. $\operatorname{PrS}$ \\
\hline & 15. TuB & & & 17. $\mathrm{CaO}$ & \\
\hline & 24. NzA & & & & \\
\hline
\end{tabular}

B.

\begin{tabular}{lllll}
\hline Population & Cluster 1 & $P$ & Cluster 2 & $P$ \\
\hline 12. TkI & 2 & 0.458 & 5 & 0.389 \\
20. MaF & 2 & 0.247 & 4 & 0.405 \\
22. AuD & 2 & 0.484 & 4 & 0.207 \\
30. ChE & 3 & 0.323 & 6 & 0.359 \\
37. CuJ & 3 & 0.335 & 4 & 0.310 \\
40. UsB & 4 & 0.158 & 6 & 0.472 \\
43. UsN & 1 & 0.375 & 4 & 0.264 \\
\hline
\end{tabular}

S1). Twenty-eight populations were attributed to a cluster with a probability higher than 0.8 , and a further group of nine populations had probability larger than 0.6. The seven remaining populations were attributed to at least two clusters (both probabilities higher than 0.2 in all cases but one). The USA populations were attributed to different clusters, and two of them to two clusters. Populations around the Mediterranean sea (South Africa and New Zealand as well) belong to a single cluster, but were not connected to USA populations. Asian populations also belong to a single group. There was otherwise little geographic cohesion. Interestingly the two Mexican populations clustered with the USA population UsD (Michigan). We further analyzed the data by considering pairwise estimates of $\mathrm{F}_{\text {st }}$ on a regional basis under the idea that single introductions followed by local spread should result in limited differentiation among populations compared to that among North American populations (0.351). The only remarkable result is the low mean pairwise estimates of $F_{\mathrm{st}}(0.120)$ exhibited by the Mos1, FL, $\mathrm{SpM}, \mathrm{PoF}$ and ItP group (i.e. populations from Italy,
Southern France, Spain and Portugal) which belong to STRUCTURE cluster 2 (Fig. 1).

\section{Discussion}

Consequences of null alleles on population structure

We detected null alleles at very high frequencies at three out of the nine loci initially considered. This result is not surprising given that $P$. acuta exhibits rather long phylogenetic branches (Wethington and Lydeard 2007) and these loci were initially cloned using individuals sampled in Southern France and Switzerland. Individuals belonging to a different branch are indeed expected to have accumulated mutations, including in the flanking regions of microsatellite loci serving as primers, leading to amplification failure (see (Dakin and Avise 2004; Selkoe and Toonen 2006). Null alleles are also likely to occur at the other six loci. RMES analysis indeed showed that 


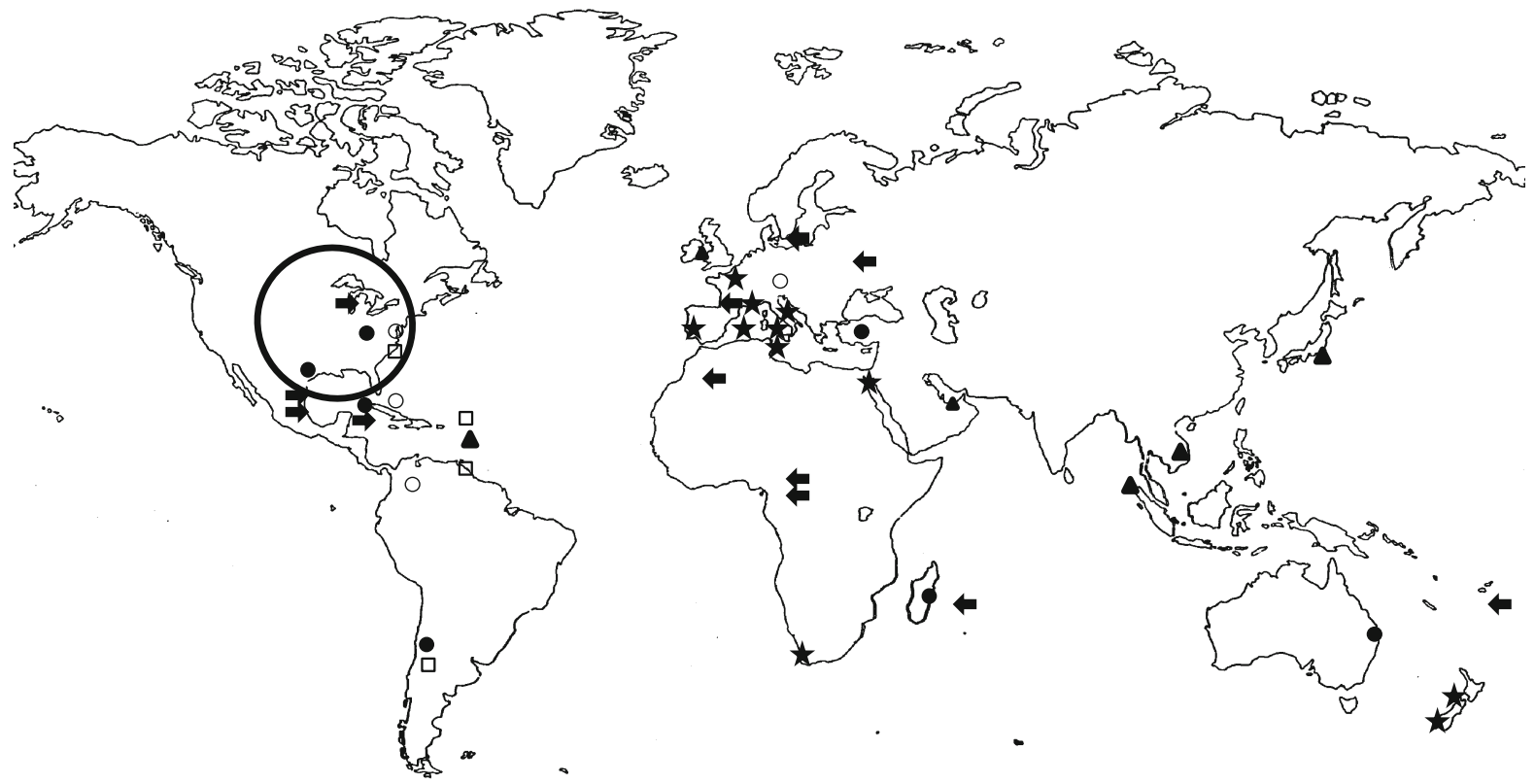

Fig. 1 Position of sampling sites (see Table 1 for geographical coordinates). The (approximative) native area of $P$. acuta (Eastern North America) is circled. Shape codes refer to STRUCTURE clusters (for populations affected to a cluster with $P>0.6$; cluster $1=$ empty circles; $2=$ stars; $3=$ empty

the populations studied are essentially outbred while the mean $F_{\text {is }}$ was 0.38. In such a situation the frequency of null alleles is about $\mathrm{F}_{\text {is }} / 2$ i.e. 0.18 (Jarne and David 2008). It is therefore not surprising that few null homozygotes were detected since their expected frequency is $0.0324\left(=0.18^{2}\right)$ and sample size was generally 12 individuals.

Intuitively the occurrence of null alleles should have a depressing effect on the variability within populations since a null allele might hide several alleles not occurring in the population (Estoup et al. 2002; but see Lemer et al. 2011). We therefore probably underestimated the within-population variation to a small extend. However populations from the native areas did not show a higher frequency of null alleles (mean $\mathrm{F}_{\text {is }}$ was 0.41). Moreover a closer look at the distribution of null homozygotes at the three loci initially excluded from the analysis of population structure and showing a high frequency of such genotypes points to the same direction: null homozygotes had a slightly higher frequency in native populations at two loci. If any, the variability in populations from the native area might have been slightly underestimated, and our conclusions on squares; 4 =triangles; $5=$ arrows pointing to the left; $6=$ arrows pointing to the right). Populations affected to two clusters are represented as plain circles. See Table 4 for more details

variation loss (see below) are not affected. A similar conclusion can be made with regard to genetic differentiation. Estimates of genetic divergence are hardly affected when null alleles are accounted for (FreeNA analysis), as expected given the low frequency of null alleles at the six loci studied (Chapuis and Estoup 2007).

Within-population genetic diversity and demography

With up to 30 alleles per locus and 1.5-5 alleles per locus and population, the amount of variability was large enough to conduct meaningful tests. Most populations showed medium to high variation with at least four polymorphic loci (out of six) in 38 populations (out of 44), and mean gene diversity over 0.3 in 39 populations. Both allelic richness and gene diversity were not significantly lower in invaded than in native areas, whether Mexican populations were counted as native or not. Four to seven bottlenecks (out of 34 populations tested) were detected depending on the mutation model assumed, all in populations outside the native area of $P$. acuta (note though that 
sample size was limited requiring caution when interpreting this result). These populations were no less variable than other populations. Even if the native area was represented by five (or seven) populations only, calling for more extensive sampling in future studies, it seems that the invasion of $P$. acuta has not been associated with variation loss within populations. Moreover wide variation was detected among populations. This is consistent with recent reviews which detected no (Wares et al. 2005; Roman and Darling 2007) or limited (Dlugosh and Parker 2008) loss of variation across a wide range of organisms. In freshwater gastropods, contrasted results have been reported. Marked loss of variation was associated with invasion of New Zealand by Lymnaea stagnalis (Kopp et al. 2012), of the Bolivian Altiplano by Lymnaea truncatula (Meunier et al. 2001) or of North America by Potamopyrgus antipodarum (Dybdahl and Drown 2011 and references therein). On the other hand, no loss occurred in Biomphalaria pfeifferi in Madagascar (Charbonnel et al. 2002) or in Melanoides tuberculata in the French Antilles (Facon et al. 2008). Invasion dates of the sites considered in the present work are not known with precision, preventing an analysis of time since invasion versus diversity. However we know that $P$. acuta has been in Europe for two centuries and in Africa for at least half a century (Brown 1994) providing ample time for multiple introductions from various sources, and the build-up of genetic variability. Such a result has been reported in other freshwater gastropods, including M. tuberculata (Facon et al. 2008) and Pomacea species (Hayes et al. 2008; Matsukara et al. 2013).

Heterozygote deficiencies were detected in a large number of populations, but they are essentially due to null alleles (see discussion above). After correction using David et al.'s method, some selfing was detected in a single population. This is consistent with what we know of the essentially outcrossing mating system of P. acuta, most populations being outcrossing and a few exhibiting selfing rates of up to ca. $30 \%$ (Jarne et al. 2000; Henry et al. 2005; Escobar et al. 2008). The population showing here some selfing is located in the invaded area. However invasion is not associated with a change in mating system towards more selfing. Such a change might be expected if inbreeding depression is purged requiring that populations go through marked bottlenecks of a few individuals (Kirkpatrick and Jarne 2000). This might also occur for purely demographic or environmental reasons: invaders might be faced with difficulties for finding reproductive partners (or pollinators in plants) (Barrett et al. 2007; Barrett 2011; Cheptou 2012). As mentioned above, this is unlikely to have been the case in $P$. acuta because of marked propagule pressure. Biological invasions are rarely associated with a change in selfing rate, as shown in plants (Barrett et al. 2007; Barrett 2011). This seems to be true in P. acuta as well, and no other case has been reported in hermaphroditic freshwater snails. It should though be noted that invading species of hermaphroditic freshwater snails are more often selfers than outcrossers (see Pointier et al. 2005, 2011), and that populations of these species in invaded areas are generally deprived in variation, showing a few genotypes only, compared to populations from native areas, in line with a suggestion by Roman and Darling (2007) and reviews in plants (Barrett et al. 2007, Barrett 2011).

Among-population differentiation and invasion phylogeography

Almost all tests revealed significant genetic differentiation among population pairs with an average $F_{\text {st }}$ value of 0.35 . This is not utterly surprising given the geographic scale of our study, and the intraspecific phylogenetic scale as well (we covered a good part of the species diversity). Wethington and Lydeard (2007) have shown that $P$. acuta exhibits pretty long phylogenetic branches based on mtDNA analysis, and Dillon and co-workers that it is a good species based on intraspecific crossings (Dillon et al. 2002, 2007, 2011). A wide range of genetic distances among populations was therefore expected (see also the discussion on null alleles above), as already observed with the same type of markers at species scale in other hermaphroditic freshwater snails (Viard et al. 1997; Mavárez et al. 2002).

The five US populations showed a similar range of $F_{\text {st }}$ values (0.212-0.708; similar conclusion when adding the two Mexican populations) suggesting that the genetic differentiation captured at worldwide scale is representative of that in the native area. We might highlight that the overall $\mathrm{R}_{\mathrm{st}}(0.337)$ falls within the confidence interval of the overall $\mathrm{F}_{\mathrm{st}}(0.326-0.389)$ suggesting that mutation contributes little to genetic differentiation, and the observed pattern can be interpreted as a migration-drift process (Hardy et al. 
2003). The spatial analysis did not reveal any strong geographic pattern or isolation by distance at study scale, even if STRUCTURE analysis detected some local genetic cohesion; for example, Western Mediterranean samples fell within cluster 2 . Neither did our analysis reveal clustering of North American populations to the exception of one population from Michigan, which together with the two Mexican populations (and the one from Puerto Rico), formed cluster 6. Seven populations, including two American ones, could not be attributed to any STRUCTURE cluster. Moreover North American populations occurred in three (to four) STRUCTURE clusters (Fig. 1).

From these results, we can draw several conclusions: (1) although our North-American sampling is somewhat weak, the variation detected in this (native) area is also found in invaded areas. Given the geographic distribution of the USA populations, this suggests that invasive populations of $P$. acuta are distributed throughout the species range. However the origin of some STRUCTURE clusters, whether geographically homogeneous (cluster 2) or heterogeneous (cluster 4), remains undetermined. (2) The geographic heterogeneity of some clusters suggests that invasion vectors may transfer $P$. acuta from local NorthAmerican areas to largely separated areas. This presumably results from human activities since it is difficult to see which biological or ecological processes would lead to such a pattern. (3) The genetic heterogeneity of some populations might be indicative of multiple invasions, or invasions from populations that are already heterogeneous (as true for at least two US populations). (4) Geographic cohesion of e.g. cluster 2 (at rather large scale) suggests invasion followed by spread, or introduction from the same source at wide geographic scale. Both multiple introductions and subsequent spread are likely given that $P$. acuta has been reported in Southern Europe for almost two centuries (see Introduction). Limited sample in North America presumably limited our inference capacity. We were also not able to use methods based on ABC (approximate Bayesian computation) inference which have proven to be efficient for reconstituting invasion routes in simpler situations (Estoup and Guillemaud 2010; Lawson Handley et al. 2011). Here the introduction histories are complex and information on introduction dates is not available preventing to implement efficiently these methods.
Limited data are available in other outcrossing hermaphroditic species - a reason is that few such species are invasive. In selfing species, strong genetic patterns have been observed, i.e. the occurrence of a few markedly different lines per site, for example in Lymnaea truncatula (Meunier et al. 2001) and B. pfeifferi (Charbonnel et al. 2002). Similar patterns have been detected in parthenogenetic freshwater gastropods, such as Melanoides tuberculata (Facon et al. 2003) and Potamopyrgus antipodarum (Städler et al. 2005), but also in bisexual gastropods such as Pomacea species (Hayes et al. 2008, Matsukara et al. 2013). Some lines (clones) have gained wide distribution at a fast pace, and it has sometimes be possible to trace back invasion routes (e.g., Meunier et al. 2001; Facon et al. 2003). In all groups, recurrent introduction and recombination may contribute to the subsequent build-up of variation blurring the genetic structure associated with the initial introduction and potentially contributing to fuel the evolutionary potential of invaders (Kolbe et al. 2004; Facon et al. 2008).

\section{Physa acuta: an exceptionally efficient invader}

Predicting what makes a good invader is a major challenge in the field of bioinvasions, perhaps an issue without general answer. Judging from its native and current distributions, $P$. acuta is an extremely efficient invader, still in the process of invading new habitats and areas (e.g., Albrecht et al. 2009). More generally, very few species have gained a cosmopolitan distribution from a rather regional one. We can offer several explanations. The first is that the migration barrier has been tresspassed (Facon et al. 2006; Davis 2008) because of extensive aquarium plant trade (Padilla and Williams 2004; Duggan 2010) and transport by waterbirds (Figuerola and Green 2002; Kappes and Haase 2012; Van Leeuwen et al. 2013). Strong propagule pressure perhaps resulted in multiple introductions. $P$. acuta is also an efficient invader at local scale: as an example, the pond network of GrandeTerre, Guadeloupe (French West Indies, ca. $800 \mathrm{~km}^{2}$ and 2,000 ponds) has been invaded in the course of a few years (PD, PJ and JPP, unpublished data). However we note that other freshwater gastropods should also have benefitted from these dispersal facilities. The second explanation has more to do with the evolutionary potential: P. acuta exhibits a wide range of variation including substantial molecular 
(this study; Bousset et al. 2004) or quantitative (e.g., Escobar et al. 2008) variation and deep evolutionary branches (Wethington and Lydeard 2007), but this is found in other poorly invasive species, such as Lymnaea peregra or Biomphalaria glabrata (Mavárez et al. 2002; Cordellier and Pfenninger 2009). It is also possible that $P$. acuta is extremely plastic with regard to both aquarium trade and natural conditions. An indirect argument is that it fares extremely well under laboratory conditions. It is also found in a wide range of environmental conditions, including strong water currents or freshwaters heavily loaded with organic matter (authors' observations). Such a niche is occupied by few species of freshwater snails, and P. acuta might have been able to draw the best on this kind of new ('dirty') niches opened by human activities. An interesting parallel can be drawn with the clonal species M. tuberculata and Tarebbia granifera, other efficient invaders occupying heavily loaded waters. Testing the idea of wide plasticity might be performed under laboratory or mesocosms conditions.

Acknowledgments We thank R. Anderson, C. Appleton, R. Bromley, P.-A. Crochet, R.T. Dillon, A. Estoup, G. Feulner, H.A. Jambari, M. Kawata, A.V. Korniushin, M. Malaquias, F. Munoz, F. Nijokou, A.M. Ramos, R. Rojas Garcia, A. Sulikowska, S. Trouve, A. Tsitrone, A. Wethington, M.J. Wallace and M. Zeki Yildirim for sampling and sending snails, P.-Y. Henry and P. Sourrouille for help with the molecular analyses, and R.T. Dillon, K.A. Hayes and three anonymous reviewers for comments on the manuscript. L. Bousset was supported by a fellowship from INRA. The project was supported by funds from CNRS to P. Jarne.

\section{References}

Albrecht C, Kroll O, Moreno Terrezas E, Wilke T (2009) Invasion of ancient Lake Titicaca by the globally invasive Physa acuta (Gastropoda: Pulmonata: Hydrophila). Biol Invasions 11:1821-1826

Barrett SCH (2011) Why reproductive systems matter for the invasion biology of plants. In: Richardson DM (ed) Fifty years of invasion biology: the legacy of Charles Elton, 1st edn. Blackwell, Oxford, pp 195-210

Barrett SCH, Colautti RI, Eckert CC (2007) Plant reproductive systems and evolution during biological invasion. Mol Ecol 17:373-383

Beisel J-N, Levêque C (2010) Introductions d'espèces dans les milieux aquatiques-Faut-il avoir peur des invasions biologiques? Quae editions

Belkhir K, Borsa P, Chikhi L, Raufaste N, Bonhomme F (2004) GENETIX 4.05, logiciel sous Windows TM pour la génétique des populations. In. Laboratoire Génome, Populations, Interactions, CNRS UMR 5171, Université de Montpellier II, Montpellier (France)

Bony YK, Kouassi NC, Diomandé D, Gourene M, VerdoitJarraya M, Pointier J-P (2007) Ecological conditions for spread of the invasive snail Physa marmorata (Pulmonata: Physidae) in the Ivory Coast. Afr Zool 43:53-60

Bousset L, Sourrouille P, Henry P-Y, Jarne P (2004) Population biology of the invasive freshwater snail Physa acuta approached through genetic markers, ecological characterization and demography. Mol Ecol 13:2023-2036

Brown DS (1994) Freshwater snails of Africa and their medical importance, 2nd edn. Taylor \& Francis Ltd, London

Chapuis M-P, Estoup A (2007) Microsatellite null alleles and estimation of population differentiation. Mol Biol Evol 24:621-631

Charbonnel N, Angers B, Rasatavonjizay R, Bremond P, Debain C, Jarne P (2002) The influence of mating system, demography, parasites and colonization on the population structure of Biomphalaria pfeifferi in Madagascar. Mol Ecol 11:2213-2228

Cheptou P-O (2012) Clarifying Baker's law. Ann Bot 109: 633-641

Cordellier M, Pfenninger M (2009) Inferring the past to predict the future: climate modelling predictions and phylogeography for the freshwater gastropod Radix balthica (Pulmonata, Basommatophora). Mol Ecol 18:534-544

Cornuet JM, Luikart G (1996) Description and power analysis of two tests for detecting recent population bottlenecks from allele frequency data. Genetics 144:2001-2014

Dakin EE, Avise JC (2004) Microsatellite null alleles in parentage analysis. Heredity 93:504-509

David P, Pujol B, Viard F, Castella E, Goudet J (2007) Reliable selfing rate estimates from imperfect population genetic data. Mol Ecol 16:2474-2487

Davis MA (2008) Invasion biology. Oxford University Press, Oxford

Dillon RT, Wethington AR (2006) The Michigan Physidae revisited: a population genetic study. Malacologia 48:133-142

Dillon RT, Wethington AR, Rhett JM, Smith TP (2002) Populations of the European freshwater pulmonate Physa acuta are not reproductively isolated from American Physa heterostropha or Physa integra. Invertebr Biol 121:226-234

Dillon RT, Robinson JD, Wethington AR (2007) Empirical estimates of reproductive isolation among the freshwater pulmonates Physa acuta, P. pomilia, and P. hendersoni. Malacologia 49:283-292

Dillon RT, Wethington AR, Lydeard C (2011) The evolution of reproductive isolation in a simultaneous hermaphrodite, the freshwater snail Physa. BMC Evol Biol 11:144. doi:10. 1186/1471-2148-11-144

Dlugosh KM, Parker IM (2008) Founding events in species invasions: genetic variation, adaptive evolution, and the role of multiple introductions. Mol Ecol 17:431-449

Duggan IC (2010) The freshwater aquarium trade as a vector for incidental invertebrate fauna. Biol Invasions 12:3757-3770

Dybdahl MF, Drown DM (2011) The absence of genotypic diversity in a successful parthenogenetic invador. Biol Invasions 13:1663-1672

Ellegren H (2004) Microsatellites: simple sequences with complex evolution. Nature Rev Genet 5:435-445 
Escobar JS, Nicot A, David P (2008) The different sources of variation in inbreeding depression, heterosis and outbreeding depression in a metapopulation of Physa acuta. Genetics 180:1593-1608

Escobar J-S, Facon B, Jarne P, Goudet J, David P (2009) Correlated evolution of mating strategy and inbreeding depression in the hermaphroditic snail Physa acuta. Evolution 63:2790-2804

Escobar JS et al (2011) Patterns of mating-system evolution in hermaphroditic animals: correlations among selfing rate, inbreeding depression and the timing of reproduction. Evolution 65:1233-1253

Estoup A, Guillemaud T (2010) Reconstructing routes of invasion using genetic data: why, how and so what? Mol Ecol 19:4113-4130

Estoup A, Cornuet J-M, Jarne P (2002) Homoplasy and mutation model at microsatellite loci and their consequence for population genetics analysis. Mol Ecol 11:1591-1604

Evanno G, Regnaut S, Goudet J (2005) Detecting the number of clusters of individuals using the software STRUCTURE: a simulation study. Mol Ecol 14:2611-2620

Facon B, Pointier J-P, Glaubrecht M, Poux C, Jarne P, David P (2003) A molecular phylogeography approach to biological invasions of the New World by parthenogenetic Thiarid snails. Mol Ecol 12:3027-3039

Facon F, Genton B, Shykoff J, Jarne P, David P, Estoup A (2006) A general eco-evolutionary framework for understanding bioinvasions. Trends Ecol Evol 21:130-135

Facon B, Pointier J-P, Jarne P, Sarda V, David P (2008) High genetic variance in life-history strategies within invasive populations by way of multiple introductions. Curr Biol 18:363-367

Falush D, Stephens M, Pritchard JK (2003) Inference of population structure using multilocus genotype data: Linked loci and correlated allele frequencies. Genetics 164:1567-1587

Figuerola J, Green AJ (2002) Dispersal of aquatic organisms by waterbirds: a review of past research and priorities for future studies. Freshw Biol 47:483-494

Goudet J, Raymond M, de Meeüs T, Rousset F (1996) Testing differentiation in diploid populations. Genetics 144:19331940

Hardy OJ, Charbonnel N, Fréville H, Heuertz M (2003) Microsatellite allele sizes: a simple test to assess their significance on genetic differentiation. Genetics 163:1467-1482

Hayes KA, Joshi RC, Thiengo SC, Cowie RH (2008) Out of South America: multiple origins of non-native apple snails in Asia. Divers Distrib 14:701-712

Henry P-Y, Bousset L, Sourrouille P, Jarne P (2005) Partial selfing, ecological disturbance and reproductive assurance in an invasive freshwater snail. Heredity 95:428-436

Jarne P, Auld JR (2006) Animals mix it up too: the distribution of self-fertilization among hermaphroditic animals. Evolution 60:1816-1824

Jarne P, David P (2008) Quantifying inbreeding in natural populations of hermaphroditic organisms. Heredity 100:431439

Jarne P, Lagoda PJL (1996) Microsatellites, from molecules to populations and back. Trends Ecol Evol 11:424-429

Jarne P, Perdieu M-A, Pernot A-F, Delay B, David P (2000) The influence of self-fertilization and grouping on fitness attributes in the freshwater snail Physa acuta: population and individual inbreeding depression. J Evol Biol 13: 645-655

Jarne P, Pointier J-P, David P, Koene J (2010) Basommatophoran Gastropods. In: Leonard JL, Córdoba-Aguilar A (eds) The evolution of "primary" sexual characters in animals. Oxford University Press, Oxford, pp 173-196

Kappes H, Haase P (2012) Slow, but steady: dispersal of freshwater molluscs. Aquat Sci 74:1-14

Kirkpatrick M, Jarne P (2000) The effect of a bottleneck on inbreeding depression and the genetic load. Am Nat 155: 154-167

Kolbe JJ, Glor RE, Schettino LRG, Lara AC, Larson A, Losos JB (2004) Genetic variation increases during biological invasion by a Cuban lizard. Nature 431:177-181

Kopp KC, Wolff K, Jokela J (2012) Natural expansion and human-assisted introduction leave different genetic signatures in a hermaphroditic freshwater snail. Evol Ecol 26:483-498

Lawson Handley L-J et al (2011) Ecological genetics of invasive alien species. Biocontrol 56:409-428

Lee CE (2002) Evolutionary genetics of invasive species. Trends Ecol Evol 17:386-391

Lemer S, Rochel E, Planes S (2011) Correction method for null alleles in species with variable microsatellite flanking regions, a case study of the black-lipped pearl oyster Pinctada margaritifera. J Hered 102:243-246

Matsukara K, Okuda M, Cazzaniga NJ, Wada T (2013) Genetic exchange between two freshwater apple snails, Pomacea canaliculata and Pomacea maculata invading East and Southeast Asia. Biol Invasions 15:2039-2048

Mavárez J, Steiner C, Delay B, Jarne P (2002) Evolutionary history and phylogeography of the schistosome-transmitting freshwater snail Biomphalaria glabrata based on nuclear and mitochondrial DNA sequences. Heredity 89:266272

Meunier C et al (2001) Lack of molluscan host diversity and the transmission of an emerging parasitic disease in Bolivia. Mol Ecol 10:1333-1340

Monsutti A, Perrin N (1999) Dinucleotide microsatellite loci reveal a high selfing rate in the freshwater snail Physa acuta. Mol Ecol 8:1076-1078

Nei M (1987) Molecular evolutionary genetics. Columbia University Press, New-York

Novak SJ, Mack RN (2005) Genetic bottlenecks in alien plant species: influence of mating systems and introduction dynamics. In: Sax DF, Gaines SD, Stachowicz JJ (eds) Species invasions - insights into ecology, evolution, and biogeography. Sinauer Associates, MA, pp 95-122

Padilla DK, Williams SL (2004) Beyond ballast water: aquarium and ornamental trades as sources of invasive species in aquatic ecosystems. Front Ecol Env 2:131-138

Pélissié B, Jarne P, David P (2012) Sexual selection without sexual dimorphism: Bateman gradients in a hermaphrodite. Evolution 66:66-81

Petit RJ, El Mousadik A, Pons O (1998) Identifying populations for conservation on the basis of genetic markers. Conserv Biol 12:844-855

Pointier J-P, David P, Jarne P (2005) Biological invasions: the case of Planorbid snails. J Helminth 79:1-9

Pointier J-P, David P, Jarne P (2011) The biological control of the snail hosts of schistosomes: the role of competitor 
snails and biological invasions. In: Toledo RFB (ed) Biomphalaria snails and larval trematodes. Springer, Berlin, pp 215-238

Pollak E (1987) On the theory of partially inbreeding finite populations. I. Partial selfing. Genetics 117:353-360

Raymond M, Rousset F (1995) GENEPOP (version 1.2): Population genetics software for exact tests and ecumenicism. J Hered 86:248-249

Roman J, Darling JA (2007) Paradox lost: genetic diversity and the success of aquatic invasions. Trends Ecol Evol 22:454-464

Rousset F (1997) Genetic differentiation and estimation of gene flow from F-statistics under isolation by distance. Genetics 145:1219-1228

Rousset F, Raymond M (1995) Testing heterozygote excess and deficiency. Genetics 140:1413-1419

Sax DF, Stachowicz JJ, Gaines SD (2005) Species invasionsinsights into ecology, evolution, and biogeography. Sinauer Associates, Sunderland

Selkoe KA, Toonen RJ (2006) Microsatellite for ecologists: a practical guide to using and evaluating microsatellite markers. Ecol Lett 9:615-629

Sourrouille P, Debain C, Jarne P (2003) Microsatellite variation in the freshwater snail Physa acuta. Mol Ecol Notes 3:21-23
Städler T, Frye M, Neiman M, Lively CM (2005) Mitochondrial haplotypes and the New Zealand origin of clonal European Potamopyrgus, an invasive aquatic snail. Mol Ecol 14:2465-2473

Van Leeuwen CHA et al (2013) How did this snail get there? Several dispersal vectors inferred for an aquatic invasive species. Freshw Biol 58:88-99

Viard F, Justy F, Jarne P (1997) The influence of self-fertilization and population dynamics on the genetic structure of subdivided populations: a case study using microsatellite markers in the freshwater snail Bulinus truncatus. Evolution 51:1518-1528

Wares JP, Hughes AR, Grosberg RK (2005) Mechanisms that drive evolutionary change: insights from species introductions and invasions. In: Sax DF, Stachowicz JJ, Gaines SD (eds) Species invasions: insights into ecology, evolution, and biogeography. Sinauer Press, Sunderland, pp 229-257

Weir BS, Cockerham CC (1984) Estimating F-statistics for analysis of population structure. Evolution 38:1358-1370

Wethington AR, Lydeard C (2007) A molecular phylogeny of Physidae (Gastropoda : Basommatophora) based on mitochondrial DNA sequences. J Molluscan Stud 73:241-257 